\title{
A case-control analysis of common variants in GIP with type 2 diabetes and related biochemical parameters in a South Indian population
}

\author{
Divya Sugunan ${ }^{1}$, Anup K Nair ${ }^{1}$, Harish Kumar², Anilkumar Gopalakrishnapillai ${ }^{\text {* }}$
}

\begin{abstract}
Background: Glucose-dependent insulinotropic polypeptide (GIP) is one of the incretins, which plays a crucial role in the secretion of insulin upon food stimulus and in the regulation of postprandial glucose level. It also exerts an effect on the synthesis and secretion of lipoprotein lipase, from adipocytes, important for lipid metabolism. The aim of our study was to do a case-control association analysis of common variants in GIP in association with type 2 diabetes and related biochemical parameters.

Method: A total of 2000 subjects which includes 1000 (584M/416F) cases with type 2 diabetes and 1000 (470M/ 530F) normoglycemic control subjects belonging to Dravidian ethnicity from South India were recruited to assess the effect of single nucleotide polymorphisms (SNPs) in GIP (rs2291725, rs2291726, rs937301) on type 2 diabetes in a case-control manner. The SNPs were genotyped by using tetra primer amplification refractory mutation systemPCR (ARMS PCR). For statistical analysis, our study population was divided into sub-groups based on gender (male and female). Association analysis was carried out using chi-squared test and the comparison of biochemical parameters among the three genotypes were performed using analysis of covariance (ANCOVA).

Result: Initial analysis revealed that, out of the total three SNPS selected for the present study, two SNPs namely rs2291726 and rs937301 were in complete linkage disequilibrium (LD) with each other. Therefore, only two SNPs, rs2291725 and rs2291726, were genotyped for the association studies. No significant difference in the allele frequency and genotype distribution of any of the SNPs in GIP were observed between cases and controls $(P>$ 0.05). Analysis of biochemical parameters among the three genotypes showed a significant association of total cholesterol $(P=0.042)$ and low density lipoprotein $(L D L)$ with the $G$ allele of the SNP rs2291726 in $G I P(P=0.004)$, but this was observed only in the case of female subjects. However this association does not remain significant after correction for multiple testing by Bonferroni's inequality method.

Conclusion: No statistically significant association was observed between any of the SNPs analysed and type 2 diabetes in our population. But the analysis of biochemical parameters indicates that the $G$ allele in rs 2291726 may be a putative risk allele for increased LDL cholesterol and further studies in other population needs to be carried out for ascertaining its role in cholesterol metabolism and subsequent cardiovascular risk.
\end{abstract}

\section{Background}

Type 2 diabetes is a complex metabolic disease, primarily characterised by insulin resistance, relative insulin deficiency and hyperglycemia [1]. According to the Diabetic Atlas 2009 published by the International Diabetic Federation, the prevalence of type 2 diabetes in

\footnotetext{
* Correspondence: g.soanil@gmail.com
'Amrita School of Biotechnology, Amrita Vishwa Vidyapeetham, Amritapuri

* Correspondence: g.soanil@gmail.com
${ }^{1}$ Amrita School of Biotechnology, Amrita Vishwa Vidyapeetham, Amritapuri PO, Kollam, Kerala, 690 525, India
}

(c) 2010 Sugunan et al; licensee BioMed Central Ltd. This is an Open Access article distributed under the terms of the Creative Commons Attribution License (http://creativecommons.org/licenses/by/2.0), which permits unrestricted use, distribution, and reproduction in any medium, provided the original work is properly cited.
Indian population is estimated to be around 51 million and India is regarded as the "diabetic capital of the world" [2]. The high prevalence of diabetes in Asian Indians and in particular, South Indian population goes along with higher adiposity, central obesity and high familial aggregation of diabetes [3]. The genetic basis of type 2 diabetes also differs considerably from the western population and efforts are going on to understand the genetic nature of type 2 diabetes in South Indian population [4-6]. 
It is a well established fact that type 2 diabetes is caused by the interplay of a triad which includes the progressive decline in insulin producing $\beta$-cells, an increase in insulin resistance and increased hepatic glucose production [7]. In addition to these, evidences from recent studies also suggest a role for gastrointestinal hormones like incretins which include GIP and glucagon-like peptide -1(GLP-1) towards the manifestation of type 2 diabetes. [8]. GIP is a single 42 amino acid peptide derived from the post-translational processing of a 153 amino acid precursor [9]. It is secreted predominantly by k-cells and released from the upper small intestine (duodenum and proximal jejunum) in response to nutrient ingestion, mainly glucose or fat rich meal $[10,11]$. This increased level of GIP induces insulin release from the pancreatic $\beta$-cells and is responsible for about $70 \%$ of postprandial insulin secretion [12]. GIP stimulates glucose-dependent insulin secretion via the activation of their specific GIP receptors (GIPR) expressed on the membrane of pancreatic beta cells. This in turn activates adnenylyl cyclase, phospholipase A and extracellular kinase (ERK and MAP), as a result of which, there is a change in the cellular ion flux ultimately aiding insulin secretion from the pancreatic beta cells [13-18].

In addition to its role in facilitating the release of insulin from pancreatic beta cells, GIP also promotes the proliferation of these cells and prevents their apoptosis hence preventing beta cell dysfunction. [19]. GIP has also been shown to stimulate adipocytes to synthesise and release lipoprotein lipase which hydrolyses lipoprotein associated triglycerides and facilitates its local uptake as free fatty acids into adipocytes [20]. Subsequent studies with GIPR-/- mice revealed that GIP is an obesity promoting factor. [21-23]. This led to the suggestion that GIPR antagonist may be useful in treating type 2 diabetes in European population where it is closely related to obesity and GIPR agonists may give a good indication with diabetes related to impaired insulin release, especially in Asia [24]. Though there is no conclusive evidence in the literature suggesting an altered expression of GIP, it has been shown that, in type 2 diabetes, the overall incretin effect is reduced and this was mainly attributed to altered functioning of GIP $[25,26]$. The physiological role of GIP in insulin release and fat metabolism combined with the fact that there is a reduction in the incretin effect in type 2 diabetes makes GIP and its receptor suitable candidate genes for genetic association studies in type 2 diabetes. Though many studies have been undertaken to analyse the role of common variants in GIPR for association with type 2 diabetes, very rarely have these studies looked at the common variants in GIP. Inke et al. analysed two SNPs, rs2291725 (G>A, Ser103Gly) and rs2291726 (A>G, a putative splice site SNP) in GIP, for association with traits of the metabolic syndrome in a case- control study in European population but failed to observe any significant difference. Further analysis of these two SNPs to analyze the association with type 2 diabetes proved to be negative [27]. However, the sample size used to detect association with type 2 diabetes was small and this study was carried out only in one population. So it is important to use a larger study group and also a different population before ruling out the possible association of GIP with type 2 diabetes.

In this study, we have used a case-control approach for analysing three common variants in GIP, rs2291725 (A>G, Ser103Gly), rs2291726 (G>A, intron-exon boundary) and rs937301 (C>T, promoter) using a total of 2000 subjects which includes $1000(584 \mathrm{M} / 416 \mathrm{~F})$ unrelated cases with type 2 diabetes and $1000(470 \mathrm{M} / 530 \mathrm{~F})$ normoglycemic control subjects belonging to South Indian population. We also report association analysis of these SNPs with age of onset of diabetes, Body Mass Index (BMI) and biochemical parameters related to type 2 diabetes.

\section{Methods}

\section{Patients and controls}

Blood samples were collected from a total of 1002 unrelated patients (584 M \& $418 \mathrm{~F}$ ) visiting the outpatient section of the endocrinology department at Amrita Institute of Medical Science (AIMS), Kochi, Kerala during the period 2008-2009. The inclusion criteria of patients for this study were: a) clinically diagnosed as type 2 diabetes, which includes the scrutinizing of medical records for symptoms, use of any medication and measuring the fasting blood glucose levels following the guidelines of American Diabetes Association [28], b) age of onset or diagnosis should be less than 60 years, c) should not have any other metabolic diseases and d) belonging to Dravidian ethnicity. Blood samples of patients from outside Kerala and patients migrating from other parts of the country were not included in the study. Subjects with monogenic forms of diabetes, drug induced diabetes or type 1 diabetes were excluded from the study. All individual and clinical characteristics of the study subjects like age, age at diagnosis, weight, height, body mass index (BMI), smoking and alcohol status, food habits, whether using insulin or not, family history of diabetes, fasting blood sugar, lipid profile and Creatinine values were taken and documented. When available, details of diabetes related complications like diabetic nephropathy, retinopathy and neuropathy were also recorded. A detailed questionnaire was included along with the informed consent form and details of other diseases and medications were taken and documented. 
Age, sex and ethnicity matched normoglycemic control subjects were recruited in the study by public advertisement and by offering screening for diabetic risk factors and its awareness, from various parts of Kerala by organizing medical camps. Each of the participants was administered to a health questionnaire which included personal and family history of the subjects, height, weight and blood pressure. Blood pressure was measured after 5 min rest in the sitting position using an automated sphygmomanometer. Fasting blood sugar for all the study participants were checked and documented. A 2 hour plasma blood sugar (PPBS) was also checked for the respective subjects and only those subjects with $\mathrm{PPBS}<140 \mathrm{mg} / \mathrm{dl}$ and a fasting blood sugar value $<110 \mathrm{mg} / \mathrm{dl}$ was included in the study. All blood samples were collected under the supervision of an attending physician. From the large number of subjects screened during this study only 1000 (470M/530F) subjects fulfilled the inclusion criteria for normoglycemic controls. All the selected normoglycemic control subjects were thoroughly screened for negative family history of diabetes. More than 500 newly diagnosed diabetic cases were reported during this screening. The inclusion criteria for the healthy controls were: a) should be above 40 years of age, b) should not have any first degree relatives with diabetes, c) should not be taking or have taken any oral hypoglycemic agent or insulin, d) should not have elevated fasting blood sugar level $(>110$ $\mathrm{mg} / \mathrm{dl}$ ) and a 2 hour post prandial blood sugar level $>140 \mathrm{mg} / \mathrm{dl}$. Clinical characterisation of the study subjects is summarized in the Table 1.

All the patients and healthy controls were explained the purpose of the study and the complications of investigative procedure. $5 \mathrm{ml}$ peripheral blood samples were collected after they signed the written informed consent. The study was approved by the institutional ethics committee [AIMS, Kochi] following the Indian Council of

Table 1 Clinical characterisation of the study population

\begin{tabular}{lcc}
\hline Characteristics & Patients (T2D) & Controls \\
\hline $\mathrm{n}$ & 1000 & 1000 \\
Sex (Male/Female) & $584 / 416$ & $470 / 530$ \\
Age (years) & $55.7 \pm 10.2$ & $51.07 \pm 10.2$ \\
Age of onset of diabetes (years) & $45.08 \pm 9.04$ & $\mathrm{NA}$ \\
$\mathrm{BMI}\left(\mathrm{Kg} / \mathrm{m}^{2}\right)$ & $25.05 \pm 3.4$ & $23.09 \pm 3.9$ \\
FBS $(\mathrm{mmol} / \mathrm{l})$ & $8.67 \pm 3.4$ & $4.9 \pm 0.58$ \\
$\mathrm{HbA} 1 \mathrm{c}(\%)$ & $8.3 \pm 1.8$ & - \\
Triglyceride (mmol/l) & $1.63 \pm 0.83$ & - \\
Total cholesterol (mmol/l) & $5.02 \pm 1.28$ & - \\
$\mathrm{HDL}(\mathrm{mmol} / \mathrm{l})$ & $1.19 \pm 0.35$ & - \\
$\mathrm{LDL}(\mathrm{mmol} / \mathrm{l})$ & $3.05 \pm 1.02$ & - \\
\hline
\end{tabular}

n: number of total subjects

Values are expressed as mean \pm SD
Medical Research guidelines for handling human samples.

\section{Genotyping and SNP analysis}

Genomic DNA was isolated from patients and healthy volunteers using salting out method [29]. DNA concentration was detected by UV-VIS spectroscopy and diluted to a final concentration of $100 \mathrm{ng} / \mu \mathrm{l}$. A total of 3 SNPs in GIP were selected for the current analysis. rs2291725 and rs2291726 were selected based on a previous study in European population. Additionally one more SNP, rs937301 was selected for the analysis which is a promoter polymorphism with a minor allele frequency $>0.1$ in the study population. SNPs were genotyped by using tetra primer ARMS PCR [30]. Each PCR reaction was carried out in a total reaction volume of $15 \mu \mathrm{l}$. Primer sequences and PCR conditions for the three SNPs have been provided in additional file 1, Table S1. The resultant products obtained after PCR were separated by electrophoresis on $2.5 \%$ agarose gel containing ethidium bromide and visualised by gel documentation system (Bio-rad, USA). Allele frequencies for each SNP were calculated by allele counting. Randomly selected $20 \%$ of samples were re-genotyped for cross validating initial genotypes. In case of unclear genotyping results, the samples were repeated again in duplicates till clear genotype was available. Unclear genotyping results, even after repetition was excluded from the study. No genotyping error was observed during cross validation. Nucleotide sequence and SNP details were obtained from SNPper http://snpper.chip. org/ and cross validated with the sequence from NCBI http://www.ncbi.nlm.nih.gov/.

\section{Statistical Analysis}

Allele and genotype frequencies were calculated for the whole cohort and analysed for any deviation from Hardy-Weinberg Equilibrium (HWE). HWE analysis was carried out with help of statistical webpage, http://ihg2. helmholtz-muenchen.de/cgi-bin/hw/hwa1.pl. Comparison of allele frequencies and genotype distributions between case and control samples were done by Pearson's chi- square test. Clinical variables such as age of diagnosis, fasting blood sugar, Creatinine and HbA1c were compared using one-way analysis of variance (ANOVA). The study population was divided into two sub-groups based on gender (male/female). The difference in BMI and lipid profile among different genotypic individual were assessed using the analysis of covariance (ANCOVA) to correct for age with respective parameters. $\mathrm{P}<0.05$ was considered to be statistically significant. All the analysis was performed using the statistical webpage, VassarStat: Statistical Computation http:// faculty.vassar.edu/lowry/VassarStats.html. Correction for 
multiple testing was done by Bonferroni's inequality method wherever applicable.

\section{Results}

Allele frequency and genotype distribution

Initial genotyping in 300 case samples and an equal number of control samples revealed that the two SNPs, rs2291726 and rs937301 are in complete LD with each other in our study population. So for further analysis only rs2291726 was genotyped. The genotype distributions of the two gene variants in GIP (rs2291725 and rs2291726) did not show significant variation from Hardy-Weinberg proportions. The allele frequency and genotype distribution of both the SNPs in cases and controls have been summarised in Table 2. The allele frequencies for the major and minor allele of rs2291725 were 0.56 and 0.44 respectively in patients as compared to 0.57 and 0.43 respectively in controls $(\mathrm{OR}=1.022$ [0.902-1.159], $P=$ 0.728 ) whereas, the allele frequencies in the case of rs2291726 for the major and minor allele were 0.53 and 0.47 respectively in patients as compared to 0.53 and 0.47 respectively in controls $(\mathrm{OR}=0.998$ [0.881-1.130], $P=$ $0.974)$. No significant difference between the genotype

Table 2 Association analysis of GIP SNPs with Type 2 Diabetes

\begin{tabular}{|c|c|c|}
\hline & rs2291725 & rs2291726 \\
\hline Major allele & $A$ & $G$ \\
\hline Minor allele & G & A \\
\hline \multicolumn{3}{|l|}{ Controls } \\
\hline n & 998 & 1000 \\
\hline Major homozygous & 325 & 297 \\
\hline Hetrozygous & 481 & 472 \\
\hline Minor homozygous & 192 & 231 \\
\hline Major allele frequency & 0.57 & 0.53 \\
\hline Minor allele frequency & 0.43 & 0.47 \\
\hline HWE (P -value) & 0.555 & 0.100 \\
\hline \multicolumn{3}{|l|}{ Cases (T2DM) } \\
\hline n & 989 & 1000 \\
\hline Major homozygous & 326 & 283 \\
\hline Hetrozygous & 458 & 501 \\
\hline Minor homozygous & 205 & 216 \\
\hline Major allele frequency & 0.56 & 0.53 \\
\hline Minor allele frequency & 0.44 & 0.47 \\
\hline HWE (P -value) & 0.060 & 0.837 \\
\hline \multicolumn{3}{|c|}{ Tests for association (C.I.: $95 \%$ confidence interval) } \\
\hline Odds ratio & 1.022 & 0.998 \\
\hline Allele frequency & 0.728 & 0.974 \\
\hline Dominant model & 0.850 & 0.490 \\
\hline Recessive model & 0.406 & 0.421 \\
\hline
\end{tabular}

$\mathrm{n}$ : total number of subjects

HWE - Hardy-Weinberg equilibrium groups were observed in both the SNPs (rs2291725 and rs2291726) among cases and controls. We also tested whether there is any significant difference in a dominant or negative model for both the SNPs but failed to observe any statistically significant difference.

\section{Association analysis with diabetes related biochemical parameters}

Association analysis of SNPs in GIP with biochemical parameters was done by using ANCOVA. For association analysis of serum lipid levels only those subjects who were not taking any cholesterol modulating drug based on the health questionnaire during sample collection were included for the analysis. We found a significant association of the SNP rs2291726 with total cholesterol and LDL in female subjects. However this association was observed only in female subjects and did not achieve the desired significance level after correction for multiple testing $[p=0.06(p \times 15$ tests $)]$. LDL showed a stronger association with the SNP rs2291726 $(\mathrm{P}=0.004)$ than total cholesterol $(\mathrm{P}=0.04)$. Interestingly we did not observe this trend in male subjects and also we did not observe any significant difference when we did a combined analysis (male and female). There was no significant association of the SNP rs2291725 with total cholesterol and LDL in males or females.

We also analysed whether the two SNPs have any role in measures of Fasting blood sugar (FBS) or BMI but failed to observe any significant association. Creatinine values also did not show any significant difference between the three genotypes in both the SNPs. And finally we analysed whether these SNPs play a role in early age of onset of diabetes in this population but did not observe any significant difference between the three genotypes in both the SNPs. The results for association analysis with biochemical parameters has been summarised in Table 3 and Table 4.

\section{Discussion}

In this study, we did a case-control analysis of common variants (rs2291726 and rs2291725) in GIP with type 2 diabetes in a South Indian population. After genotyping 1000 type 2 diabetic samples and 1000 control samples, we failed to observe any significant association of these SNPs with type 2 diabetes in our population. An association study in one of the European population also did not reveal any significant association of these SNPs with traits of metabolic syndrome or with type 2 diabetes, though the sample size to detect an association with type 2 diabetes was low [27]. Since the role of GIP in the manifestation of type 2 diabetes seems to be different among Europeans and Asians it is important to replicate association studies of GIP in Asian population as well [24]. 
Table 3 Association analysis of SNPs rs 2291725with biochemical parameters in diabetes

\begin{tabular}{|c|c|c|c|c|c|c|}
\hline & AA & GA & GG & TOTAL & $P$ & $P^{*}$ \\
\hline Age of on set of diabetes (years) & $44.64 \pm 9.14$ & $45.88 \pm 8.77$ & $44.16 \pm 9.45$ & $45.13 \pm 9.05$ & 0.064 & NA \\
\hline Fasting Blood Glucose (mmol/l) & $8.77 \pm 3.02$ & $8.675 \pm 3.76$ & $8.50 \pm 3.34$ & $8.67 \pm 3.44$ & 0.726 & NA \\
\hline \multicolumn{7}{|l|}{ BMI $\left(K g / m^{2}\right)$} \\
\hline Male & $24.26 \pm 3.08$ & $24.53 \pm 3.37$ & $24.57 \pm 2.95$ & $24.46 \pm 3.19$ & 0.664 & 0.671 \\
\hline Female & $25.92 \pm 3.67$ & $26.08 \pm 3.41$ & $26.16 \pm 3.65$ & $26.04 \pm 3.54$ & 0.896 & 0.905 \\
\hline \multicolumn{7}{|l|}{ Total Cholesterol $(\mathrm{mmol} / \mathrm{l})$} \\
\hline Male & $4.97 \pm 1.22$ & $4.95 \pm 1.28$ & $4.98 \pm 1.11$ & $4.96 \pm 1.23$ & 0.980 & 1.000 \\
\hline Female & $5.28 \pm 1.28$ & $5.08 \pm 1.27$ & $5.02 \pm 1.02$ & $5.14 \pm 1.22$ & 0.404 & 0.366 \\
\hline \multicolumn{7}{|l|}{ Triglyceride (mmol/l) } \\
\hline Male & $1.69 \pm 0.91$ & $1.59 \pm 0.80$ & $1.64 \pm 0.81$ & $1.63 \pm 0.89$ & 0.601 & 0.691 \\
\hline Female & $1.56 \pm 0.64$ & $1.63 \pm 0.78$ & $1.67 \pm 0.81$ & $1.62 \pm 0.74$ & 0.684 & 0.779 \\
\hline \multicolumn{7}{|l|}{$\mathrm{HDL}(\mathrm{mmol} / \mathrm{l})$} \\
\hline Male & $1.19 \pm 0.50$ & $1.15 \pm 0.34$ & $1.15 \pm 0.26$ & $1.16 \pm 0.38$ & 0.677 & 0.684 \\
\hline Female & $1.23 \pm 0.29$ & $1.23 \pm 0.31$ & $1.28 \pm 0.25$ & $1.24 \pm 0.29$ & 0.607 & 0.583 \\
\hline \multicolumn{7}{|l|}{ LDL (mmol/l) } \\
\hline Male & $2.93 \pm 0.89$ & $3.09 \pm 1.06$ & $3.08 \pm 0.94$ & $3.04 \pm 0.99$ & 0.344 & 0.279 \\
\hline Female & $3.27 \pm 1.03$ & $3.13 \pm 0.98$ & $3.04 \pm 0.81$ & $3.25 \pm 0.97$ & 0.362 & 0.318 \\
\hline HbA1c (\%) & $8.44 \pm 1.98$ & $8.33 \pm 1.78$ & $8.21 \pm 1.75$ & $8.34 \pm 1.85$ & 0.549 & NA \\
\hline \multicolumn{7}{|l|}{ Creatinine $(\mu \mathrm{mol} / \mathrm{l})$} \\
\hline Male & $102.92 \pm 45.40$ & $102.12 \pm 29.73$ & $109.67 \pm 32.24$ & $103.83 \pm 35.98$ & 0.238 & NA \\
\hline Female & $84.29 \pm 24.53$ & $82.06 \pm 20.37$ & $84.93 \pm 27.29$ & $83.49 \pm 23.44$ & 0.684 & NA \\
\hline
\end{tabular}

* $P$ value adjusted for age, Number of sample analysed for lipid profile - Male=411, Female- 250, Creatinine - Male-450, Female- 280 . NA: Not Applicable. Datas are expressed as mean \pm SD

Table 4 Association analysis of SNPs rs 2291726 with biochemical parameters in diabetes

\begin{tabular}{|c|c|c|c|c|c|c|}
\hline & AA & AG & GG & TOTAL & $\mathbf{P}$ & $\mathrm{P}^{*}$ \\
\hline Age of on set of diabetes (years) & $44.04 \pm 8.69$ & 45. $24 \pm 8.82$ & $45.02 \pm 8.53$ & $44.92 \pm 8.72$ & 0.287 & NA \\
\hline Fasting Blood Glucose (mmol/l) & $8.572 \pm 3.23$ & $8.709 \pm 3.45$ & $8.61 \pm 3.10$ & $8.65 \pm 3.31$ & 0.869 & NA \\
\hline \multicolumn{7}{|l|}{ BMI $\left(\mathrm{Kg} / \mathrm{m}^{2}\right)$} \\
\hline Male & $24.21 \pm 2.98$ & $24.64 \pm 3.38$ & $24.29 \pm 2.99$ & $24.45 \pm 3.19$ & 0.419 & 0.415 \\
\hline Female & $26.31 \pm 3.86$ & $26.01 \pm 3.46$ & $25.83 \pm 3.42$ & $26.02 \pm 3.54$ & 0.691 & 0.719 \\
\hline \multicolumn{7}{|l|}{ Total Cholesterol $(\mathrm{mmol} / \mathrm{l})$} \\
\hline Male & $5.07 \pm 1.15$ & $4.97 \pm 1.28$ & $4.86 \pm 1.19$ & $4.96 \pm 1.23$ & 0.477 & 0.549 \\
\hline Female & $4.89 \pm 1.05$ & $5.09 \pm 1.29$ & $5.41 \pm 1.21$ & $5.13 \pm 1.23$ & 0.050 & 0.042 \\
\hline \multicolumn{7}{|l|}{ Triglyceride (mmol/l) } \\
\hline Male & $1.68 \pm 1.03$ & $1.61 \pm 0.81$ & $1.70 \pm 0.93$ & $1.65 \pm 0.89$ & 0.632 & 0.533 \\
\hline Female & $1.59 \pm 0.79$ & $1.67 \pm 0.81$ & $1.55 \pm 0.55$ & $1.62 \pm 0.74$ & 0.538 & 0.578 \\
\hline \multicolumn{7}{|l|}{$\mathrm{HDL}(\mathrm{mmol} / \mathrm{l})$} \\
\hline Male & $1.16 \pm 0.26$ & $1.16 \pm 0.34$ & $1.17 \pm 0.51$ & $1.16 \pm 0.38$ & 0.990 & 0.990 \\
\hline Female & $1.29 \pm 0.25$ & $1.29 \pm 0.31$ & $1.24 \pm 0.29$ & $1.24 \pm 0.29$ & 0.309 & 0.321 \\
\hline \multicolumn{7}{|l|}{$\mathrm{LDL}(\mathrm{mmol} / \mathrm{l})$} \\
\hline Male & $3.09 \pm 0.99$ & $3.09 \pm 1.05$ & $2.84 \pm 0.85$ & $3.03 \pm 0.99$ & 0.097 & 0.152 \\
\hline Female & $2.89 \pm 0.85$ & $3.11 \pm 0.98$ & $3.43 \pm 0.98$ & $3.16 \pm 0.97$ & 0.005 & 0.004 \\
\hline HbA1c (\%) & $8.288 \pm 1.76$ & $8.388 \pm 1.83$ & $8.33 \pm 1.98$ & $8.35 \pm 1.85$ & 0.869 & NA \\
\hline \multicolumn{7}{|l|}{ Creatinine $(\mu \mathrm{mol} / \mathrm{l})$} \\
\hline Male & $111.05 \pm 37.45$ & $106.75 \pm 43.04$ & $99.94 \pm 39.25$ & $105.81 \pm 40.99$ & 0.119 & NA \\
\hline Female & $83.97 \pm 27.27$ & $81.58 \pm 17.26$ & $85.01 \pm 25.48$ & $83.16 \pm 22.37$ & 0.507 & NA \\
\hline
\end{tabular}

* $P$ value adjusted for age, Number of sample analysed for lipid profile - Male=411, Female- 250, Creatinine - Male-450, Female- 280. NA: Not Applicable. Datas are expressed as mean \pm SD 
GIP is known to increase fat uptake by promoting the synthesis and secretion of lipoprotein lipase, which in turn breaks down triglyceride to free fatty acids, readily available for local uptake [20]. Infact it has been seen that mice lacking GIPR did not gain weight and develop adiposity in high fat fed conditions and also utilised fat as the preferred source of energy. This suggests that GIP is an obesity promoting factor $[21,22]$. At the same time GIP is known to promote the release of insulin upon nutrient ingestion and thus helps in maintaining a proper blood glucose homeostasis $[12,31,32]$. In Europeans, who are more prone to obesity induced diabetes, blocking of GIP action on adipocytes may be more beneficial whereas it has been suggested that in Asians, GIP agonists may have a beneficial effect due to greater incidences of diabetes with impaired insulin secretion [24]. Though we did not observe any significant association of the studied polymorphisms with type 2 diabetes in our study population, we suggest a detailed genetic analysis of SNPs in GIP in other Asian populations as well.

To know more about the genetic role of these variants, we extended our studies to the biochemical parameters associated with type 2 diabetes. Interestingly, our association studies revealed a significant association of the SNP rs2291726 with total cholesterol $(P=0.042)$ and LDL $(P$ $=0.004)$ in females. But this association was not observed in males or during combined analysis (males and females). Sex related association is not a unique phenomenon and there have been studies which report sex dependent association of polymorphism in genes related to cholesterol metabolism suggesting a possible role of sex hormones [33]. Infact it has been shown that estrogen has an important role in regulating serum cholesterol levels and results in a lowering of LDL cholesterol and triglycerides and hence relatively protects younger women from cardiovascular diseases [34]. It is interesting to note that a study by Isken et.al. in mice has shown an interactive role of estrogen and GIP signalling in obesity but the molecular mechanism involved in this interaction still needs elucidation. The study reported that GIPR-/mice were resistant to ovariectomy induced obesity [35]. It has also been proposed that hormonal therapy in post menopausal women can significantly alter the enteroinsular axis which also involves GIP [35]. GIP has also been shown to play an important role in fat metabolism related diseases like non-alcoholic fatty liver disease (NAFLD) and due to its important role in cholesterol metabolism, an altered expression or function of GIP may play a role in the pathogenesis of cardiovascular diseases as well $[36,37]$. In our study we observed a significant association $(P=0.004)$ of LDL cholesterol with the SNP rs2291726 in GIP which is in complete LD with the promoter polymorphism rs937301, but the association was observed only in case of female subjects suggesting a role for sex hormones in this process. Though the association failed to reach the desired significance level after correction for multiple testing $(P=0.06)$, it should be noted that the number of female subjects included in the analysis for LDL levels were comparatively less $(n=250)$. Hence, we suggest further studies in other population with a higher sample size for the analysis of the role of this variant and LDL cholesterol levels particularly in female subjects. It is also interesting to note that post menopausal women are at a higher risk of cardiovascular diseases. LDL being the bad cholesterol is a major risk factor for cardiovascular disease and our study warrants the need of further association studies in other population and functional studies of GIP in relation to estrogen to better understand its role in cholesterol metabolism and cardiovascular diseases. An earlier study in European population looked at the role of common variants in GIPR and GIP with cardiovascular diseases. But no significant association was observed between these common variants and cardiovascular diseases. The study did report a positive association of the GIPR SNP with HDL but no results was provided for association analysis of biochemical parameters in diabetes and SNPs in GIP [27].

A recent paper by Juris et al. analysed the expression, metabolism and clearance of GIP in human with renal insufficiency [38]. They observed an increased expression of GIP in cases of renal insufficiency. This led us to analyse the association of these SNPs with serum creatinine levels. We also looked at whether these SNPs are associated with diabetic nephropathy in a study population of 400 subjects comprising of 184 subjects with renal insufficiency and 216 control subjects (data not shown). We did not find any significant association with either serum creatinine or diabetic nephropathy.

\section{Conclusion}

The present study indicates that there is no significant association between the GIP SNPs, rs2291725, rs2291726 and rs937301 and type 2 diabetes in a South Indian Dravidian population. The result of association analysis of the biochemical parameters of SNP rs2291726 shows a significant association with total cholesterol and LDL in the female subjects suggesting a role for sex hormones in the process but the association does not remain significant after correction for multiple testing

\section{Additional material}

Additional file 1: Primer sequence and PCR conditions for amplification of GIP SNPs. Oligoneucleotide sequence and PCR condition for the allele specific genotyping of three SNPs in GIP. 


\section{Abbreviations}

GIP: Glucose-dependent insulinotropic peptide, GLP-1: Glucagon-like peptide-1, HDL: High density lipoprotein, LDL: Low density lipoprotein, VLDL: Very low density lipoprotein, ANOVA: Analysis of variance, ANCOVA: Analysis of covariance, SNP: Single nucleotide polymorphism, PCR: Polymerase chain reaction, HWE: Hardy- Weinberg equilibrium, Cl: Confidence interval at 95\%, LD: Linkage disequilibrium, SNP: Single nucleotide polymorphism, NAFLD: Non-alcoholic fatty liver disease, ARMS PCR: Amplification refractory mutation system-PCR.

\section{Acknowledgements}

We thank all volunteers who participated in this study. We particularly thank Mr. Sanil Kumar who is always with us in collecting the control samples. We also thank all the lab mates and nursing staffs who supported us in sample collection. AKN has a scholarship from Council of Scientific Industrial Research, India.

\section{Author details}

${ }^{1}$ Amrita School of Biotechnology, Amrita Vishwa Vidyapeetham, Amritapuri PO, Kollam, Kerala, 690 525, India. ${ }^{2}$ Amrita Institute of Medical Science, Amrita Vishwa Vidyapeetham, AIMS Ponekkara PO, Kochi, Kerala, 682 041, India.

\section{Authors' contributions}

DS did the sample collection, genotyping, data analysis, statistical analysis, contributed to the study design and prepared the manuscript. AKN did the sample collection, statistical analysis and contributed to the study design. HK provided the case samples and monitored the overall progress of sample collection, GA prepared the study design, critically reviewed the statistical analysis and manuscript and monitored the overall progress of the project. All authors read and approved the final manuscript.

\section{Competing interests}

The authors declare that they have no competing interests.

Received: 28 February 2010 Accepted: 30 July 2010

Published: 30 July 2010

\section{References}

1. Prudente $S$, Morini $E$, Trischitta $V$ : Insulin signaling regulating genes: effect on T2DM and cardiovascular risk. Nat Rev Endocrinol 2009, 12:682-693.

2. Unwin N, Whiting D, Gan D, Jacqmain O, Ghyoot G: International Diabetes Federation Diabetes Atlas. IDF Diabetes Atlas International Diabetes Federation, Belgium, Fourth 2009

3. Ramachandran A, Snehalatha C, Viswanathan V, Viswanatha M, Haffner SM: Risk of non insulin dependent diabetes mellitus conferred by obesity and central adiposity in different ethnic groups: a comparative analysis between Asian Indians, Mexican Americans and Whites. DiabetesRes Clin Pract 1997, 36:121-125

4. Radha V, Vimaleswaran KS, Babu HNS, Abate N, Chandalia M, Satija P, Grundy SM, Ghosh S, Majumder PP, Deepa R, Rao SMR, Mohan V: Role of genetic polymorphism peroxisome proliferator - Activated Receptor - 2 Pro 12Ala on ethnic susceptibility to diabetes in south Asian and caucasian subjects. (CURES-5). Diabetes Care 2006, 29:1046-1051.

5. Vimaleswaran KS, Radha V, Ghosh S, Majumder PP, Deepa R, Babu HNS, Rao MRS, Mohan V: Peroxisome proliferators-activated receptor- coactivator -1 (PGC-1) gene polymorphisms and their relationship to Type 2 diabetes in Asian Indians (CURES-14). Diabetic Medicine 2005, 22:1516-1521.

6. Vimaleswaran KS, Radha V, Ramya K, Babu HNS, Savitha N, Roppa V, Monalisa D, Deepa R, Ghosh S, Majumder PP, Rao MRS, Mohan V: A novel association of polymorphism in the first intron of adiponectin gene with type 2 diabetes, obesity and hypoadiponectinemia in Asian Indians. Human Genetics 2008, 123:599-605.

7. Pratley RE, Weyer $C$ : The role of impaired early insulin secretion in the pathogenesis of Type II diabetes mellitus. Diabetologia 2001, 44:929-945.

8. Nauck MA, Baller B, Meier JJ: Gastric inhibitory polypeptide and glucagonlike peptide- 1 in the pathogenesis of type 2 diabetes. Diabetes 2004, 53(Suppl 3):S190-S196

9. Takeda J, Seino Y, Tanaka K, Fukumoto H, Kayano T, Takahashi H, Mitani T, Kurono M, Suzuki T, Tobe T, Imuru H: Sequence of an intestinal cDNA encoding human gastric inhibitory polypeptide precursor. Proc Natl Acad Sci USA 1987, 84(20):7005-7008.

10. Buchan AM, Polak JM, Capella C, Solcia E, Pearse AG: Electron immunochemical evidence for the $\mathrm{K}$ cell localization of gastric inhibitory polypeptide (GIP) in man. Histochemistry 1978, 56:37-44.

11. Mortensen K, Christensen LL, Holst JJ, Orskov C: GLP-1 and GIP are colocalized in a subset of endocrine cells in the small intestine. Regul Pept 2003, 114:189-196.

12. Dupre J, Ross SA, Watson D, Brown JC: Stimulation of insulin secretion by gastric inhibitory polypeptide in man. J Clin Endocrinol Metab 1973, 37:826-828.

13. Ehses JA, Lee SST, Pederson RA, McIntosh CHS: A new pathway for glucose-dependent insulinotropic polypeptide (GIP) receptor signalingEvidence for the involvement of phospholipase A, in GIP-stimulated insulin secretion. J Biol Chem 2001, 276:23667-23673.

14. Wheeler MB, Gelling RW, McIntosh CH, Georgiou J, Brown JC, Pederson RA: Functional expression of the rat pancreatic islet glucose- dependent insulinotropic polypeptide receptor: ligand binding and intracellular signaling properties. Endocrinology 1995, 136:4629-4639.

15. Trumper A, Trumper K, Trusheim H, Arnold R, Goke B, Horsch D: GlucoseDependent Insulinotropic Polypeptide Is a Growth Factor for b (INS-1) Cells by Pleiotropic Signaling. Mol Endocrinol 2001, 15:1559-1570.

16. Beguin P, Nagashima K, Nishimura N, Gonoi T, Seino S: PKA mediated phosphorylation of the human K-ATP channel: separate roles of Kir6.2 and SUR1 subunit phosphorylation. EMBO J 1999, 18:4722-4732.

17. Ding WG, Gromada J: Protein kinase A-dependent stimulation of exocytosis in mouse pancreatic beta-cells by glucose-dependent insulinotropic polypeptide. Diabetes 1997, 46:615-621.

18. McIntosh CH, Wheeler MB, Gelling RW, Brown JC, Pederson RA: GIPRs and signal-transduction mechanisms. Acta Physiol Scand 1996, 157:361-365.

19. Ehses JA, Casilla VR, Doty T, Pospisilik JA, Demuth HU, Pederson RA, Winter KD, Mclntosh CH: Glucose-dependent Insulinotropic Polypeptide (GIP) Promotes \{beta\}-(INS-1) cell survival via cyclic AMP-mediated caspase-3 inhibition and regulation of p38 MAP kinase. Endocrinology 2003, 144:4433-4445.

20. Eckel RH, Fujimoto WY, Brunzell JD: Gastric inhibitory polypeptide enhanced lipoprotein lipase activity in cultured preadipocytes. Diabetes 1979, 28:1141-1142.

21. Miyawaki K, Yamada $Y$, Ban N, Ihara Y, Tsukiyama K, Zhou H, Fujimoto S, Oku A, Tsuda K, Toyokuni S, Hiai H, Mizunoya W, Fushiki T, Holst JJ, Makino M, Tashita A, Kobara Y, Tsubamoto Y, Jinnouchi T, Jomori T: Inhibition of gastric inhibitory polypeptide signaling prevents obesity. Nat Med 2002, 8:738-742.

22. Creutzfeldt W, Ebert R, Willms B, Frerichs H, Brown JC: Gastric inhibitorypolypeptide (GIP) and insulin in obesity: increased response to stimulation and defective feedback control of serum levels. Diabetologia 1978, 14:15-24.

23. Flatt PR, Bailey CJ, Kwasowski P, Swanston-Flatt SK, Marks V: Abnormalities of GIP in spontaneous syndromes of obesity and diabetes in mice. Diabetes 1983, 32:433-435.

24. Yamada Y, Miyawaki K, Tsukiyama K, Harada N, Yamada C, Seini Y: Pancreatic and extrapancreatic effects of gastric inhibitory polypeptide. Diabetes 2006, 55(Suppl 2):S86-S91.

25. Nauck MA, Stöckmann F, Ebert R, Creutzfeldt W: Reduced incretin effect in type 2 (non-insulin-dependent) diabetes. Diabetologia 1986, 29:46-52.

26. Vilsbø\|l T, Krarup T, Deacon CF, Madsbad S, Holst JJ: Reduced postprandial concentrations of intact biologically active glucagon-like peptide 1 in type 2 diabetic patients. Diabetes 2001, 50:609-13.

27. Nitz I, Fisher E, Weikert C, Burwinkel B, Li Y, Möhlig M, Boeing H, Schreiber S, Schrezenmeir J, Döring F: Association analyses of GIP and GIPR polymorphisms with traits of the metabolic syndrome. Mol Nutr Food Res 2007, 51(8):1046-52.

28. Diagnosis and classification of diabetes mellitus. Diabetes care 2004, 27(Suppl 1):S5-S10.

29. Miller SA, Dykes DD, Polesky HF: A simple salting out procedure for extracting DNA from human nucleated cells. Nucleic acids research 1988, 16(3):1215.

30. Ye S, Dhillon S, Ke X, Collins AR, Day IN: An efficient procedure for genotyping single nucleotide polymorphisms. Nucleic Acids Research 2001, 29, No. 17 e88. 
31. McIntyre N, Holsworth DC, Turner DS: New interpretation of oral glucose tolerance. Lancet 1964, 2:20-21.

32. Elrick H, Stimmler L, Hlad CJ Jr, Arai Y: Plasma insulin response to oral and intravenous glucose administration. J Clin Endocrinol Metab 1964, 24:1076-1082.

33. Chiba-Falek O, Nichols M, Suchindran S, Guyton J, Ginsburg GS, BarrettConnor E, McCarthy JJ: Impact of gene variants on sex-specific regulation of human Scavenger receptor class B type 1 (SR-BI) expression in liver and association with lipid levels in a population-based study. BMC Med Genet 2010, 11:9.

34. Bush $T L$, Fried LP, Barrett-Connor E: Cholesterol, lipoproteins, and coronary heart disease in women. Clin Chem 1988, 34(8B):B60-70.

35. Isken F, Pfeiffer AF, Nogueiras R, Osterhoff MA, Ristow M, Thorens B, Tschöp MH, Weickert MO: Deficiency of Glucose-Dependent Insulinotropic Polypeptide (GIP) receptor prevents ovariectomy-induced obesity in mice. Am J Physiol Endocrinol Metab 2008, 295(2):E350-355.

36. Musso G, Gambino R, Pacini G, De Michieli F, Cassader M: Prolonged saturated fat-induced, glucose-dependent Insulinotropic polypeptide elevation is associated with adipokine imbalance and liver injury in nonalcoholic steatohepatitis: dysregulated enteroadipocyte axis as a novel feature of fatty liver. Am J Clin Nutr 2009, 89:558-567.

37. Kim SJ, Nian C, Mclntosh CH: Resistin is a key mediator of glucose dependent insulinotropic polypeptide (GIP) stimulation of lipoprotein lipase (LPL) activity in adipocytes. J Biol Chem 2007, 282:34139-34147.

38. Meier JJ, Nauck MA, Kranz D, Holst JJ, Deacon CF, Gaeckler D, Schmidt WE, Gallwitz B: Secretion, Degradation, and Elimination of Glucagon-Like Peptide 1 and Gastric Inhibitory Polypeptide in Patients with Chronic Renal Insufficiency and Healthy Control Subjects. Diabetes 2004, 53(3):654-662

\section{Pre-publication history}

The pre-publication history for this paper can be accessed here: http://www.biomedcentral.com/1471-2350/11/118/prepub

doi:10.1186/1471-2350-11-118

Cite this article as: Sugunan et al:: A case-control analysis of common variants in GIP with type 2 diabetes and related biochemical parameters in a South Indian population. BMC Medical Genetics 2010 11:118

\section{Submit your next manuscript to BioMed Central and take full advantage of:}

- Convenient online submission

- Thorough peer review

- No space constraints or color figure charges

- Immediate publication on acceptance

- Inclusion in PubMed, CAS, Scopus and Google Scholar

- Research which is freely available for redistribution 